\title{
Procesos alegóricos en torno a lo natural devenido cultural. El caso de la obra videográfica "El lenguaje"
}

Juan del Junco ${ }^{1}$

${ }^{1}$ Universidad de Málaga. juandeljunco@uma.es

\begin{abstract}
This paper aims to analyse the juxtaposition of allegorical processes present in the video work "El lenguaje", (2013). In this work, from the position of the "other" - of the artist as an anthropologist - we create a montage in which we string together a documentation of the sounds emitted by goatherds in various areas of Andalusia.
\end{abstract}

The work recovers the historical division of human beings between shepherds and farmers, a division that is stipulated as two antagonistic models of inhabiting the world: one linked to place, space and work fixed in property; and the other regulated by dynamic processes, in a continuous movement through the landscape. The parallelism lies in the very idea of the artist as a nomad, a figure in permanent circulation through the conceptual and material flow of the different projects. This creative subject is perceived as distanced from the models demanded by productivism, so much in vogue by the predominant subjects of the omnipresent STEM.

The starting point is a singular vision of the experiential landscape, of the travelled and travelled landscape, understood as an artefactualised construct where there is room not only for the natural elements that make it up, but also for the cultural and identity forms that cross $i t$. It is in these less visible models of the country made landscape where we find the heritage value of the natural turned cultural.

Behind the façade of a document, a record of data from the ways of a particular collective, the work is itself an allegory. Through the figure of the goatherd and the sounds he makes to communicate with the flock, we reflect on the art system itself, the communicative process involved in the artistic statement and the notion of collectivity: of the clan.

Keywords: experiential landscapes, nomadism, transdisciplinary, video. 


\section{Resumen}

Esta comunicación pretende analizar la yuxtaposición de procesos alegóricos presentes en la obra videográfica "El lenguaje", (2013). En dicha obra, desde la posición del "otro" - del artista como antropólogo- realizamos un montaje donde encadenamos una documentación de los sonidos emitidos por los cabreros de varias zonas de Andalucía

La obra recupera la histórica división del ser humano entre pastores y agricultores, división que se estipula como dos modelos antagónicos de habitar el mundo: uno ligado al lugar, al espacio y al trabajo fijado en la propiedad; y la otra regulada por procesos dinámicos, en un movimiento continuo por el paisaje. El paralelismo recae en la propia idea del artista como nómada, una figura en circulación permanente a través del flujo conceptual y material de los distintos proyectos. Este sujeto creativo se percibe alejado de los modelos exigidos por el productivismo, tan en boga por las materias predominantes de las omnipresentes STEM.

El punto de partida es una visión singular del paisaje experiencial, del paisaje recorrido y transitado; entendiéndose éste como un constructo artealizado donde hay cabida no sólo de los elementos naturales que lo conforman, sino, además, de aquellas formas culturales y de identidad que lo atraviesan. Es en estos modelos menos visibles del país hecho paisaje donde encontramos el valor patrimonial de lo natural devenido cultural.

Tras la fachada de documento, de registro de datos provenientes de los modos de un colectivo particular, la obra es en sí misma una alegoría. A través de la figura del cabrero y de los sonidos que éste emite para comunicarse con el rebaño, realizamos una reflexión sobre el propio sistema del arte, el proceso comunicativo implicado en el enunciado artístico y la noción de colectividad: del clan.

Palabras clave: paisaje experiencial, nomadismo, transdisciplina, video.

\section{Introducción}

Evoramonte, un pequeño pueblo del Alentejo profundo cuya población de apenas setecientos habitantes vive casi exclusivamente de las labores del campo. Tras una larga caminata entre alcornoques en búsqueda de un dolmen nos disponemos a comer en un bar de no más de cinco mesas. Mientras esperamos a que nos atiendan las dos señoras sexagenarias que lo regentan observamos con ávida curiosidad la decoración del establecimiento. Entre los objetos de diversa índole nos llama la atención una imagen no más grande que el tamaño de una cuartilla colgada en una de las paredes. En ella aparece un pastor tumbado en mitad del monte, el cual parece dormir 
apoyando su cabeza en un viejo zurrón gastado. Viste pobremente y protege su cara del sol con un enorme sombrero negro. Junto a él descansa su herramienta de trabajo: un largo bastón de palo. Al fondo se pueden apreciar algunas ovejas que pastan plácidamente. Bajo la imagen se puede leer: "No molestar que estoy trabajando".

Esta imagen popular hecha visible a modo de meme en una red social pre-internet -el bar del pueblo hace de red social para los habitantes de la freguesía- podría resumir gran parte de la narrativa externa que regula nuestra obra videográfica El Lenguaje, 2014. Con esta comunicación pretendemos analizar dicha narrativa, la cual articula una alegoría entre la propia identidad y profesión del artista y las labores del cabrero; profesiones que, más allá de la dureza y obligaciones del trabajo, arrastran tanto el nomadismo como la posibilidad de atender a la riqueza y belleza del paisaje circundante. Como veremos, a la realización de la obra se llega mediante un proceso transdisciplinario de inmersión en el mundo natural al instaurar como escenario de la propuesta un modelo de paisaje experiencial. Un paisaje-lugar-territorio transitado en origen mediante la práctica de la ornitología amateur; práctica que aporta un régimen escópico regulado por un modo de observación focalizada en todos aquellos elementos que conforman el medio: desde una piedra en el suelo hasta la posibilidad de un paisaje habitado, identitario y cultural.

\section{Pastores y agricultores}

Efectivamente, en el ámbito rural se percibe cierta burla sobre el nivel de severidad en el trabajo de los pastores y cabreros en comparación con aquel que realizan los agricultores. Y es que, más allá del sarcasmo, el chiste visual de la venta portuguesa es reflejo de una división de las condiciones de trabajo y de dos maneras contrapuestas de entender el mundo: la antigua división entre pastores y agricultores; los primeros, nómadas y errantes, y los segundos apegados a los límites y márgenes del terreno y de la propiedad. Si bien ambos trabajan de sol a sol, al pastor, en su errabundeo, en su experiencia en los paisajes o territorios cambiantes, le aguardan momentos de soslayo sentado bajo un árbol -incluso tumbado-esperando a que su rebaño paste; cuando no caminando por las veredas, desplazándose con parsimonia junto a su rebaño. La suya es una jornada de trabajo que, a veces, podría equipararse a un largo paseo placentero. El pastor no tiene apego a un territorio propio ni circunscribe sus labores a la propiedad limitada, discurre de territorio en territorio, traspasando los bordes y las fronteras de los lugares acotados.

Francesco Careri (2014) nos retrotrae nada menos que al Génesis para armar el discurso de la clásica división del trabajo, aportando una reflexión sobre dos modos de estar en el territorio: “[...] la primitiva separación entre nómadas y sedentarios traería como consecuencia dos maneras de habitar el mundo, y por tanto de concebir el 
espacio" (p. 23). El arquitecto relata la malograda relación entre los hermanos Caín y Abel. Caín agricultor, limitado a su propio terreno de labor; Abel pastor y nómada, en tránsito permanente. Esta segunda generación de habitantes del mundo recibe la tierra en herencia de manos de sus padres, Adán y Eva, “[...] un mundo repartido equitativamente: a Caín le correspondió la propiedad de la tierra y a Abel la de todos los seres vivos" (Ibídem, p. 23). De este modo, podríamos pensar que esta división conlleva implícita la capacidad móvil del ser animal. Así, frente a lo estático de la plantación -únicamente en movimiento en el crecimiento en vertical- el animal, como el hombre, se desplaza en el ilimitado plano horizontal, discurre entre espacios coincidentes, tiene ante sí cierto horizonte de libertad.

Sin embargo, para el agricultor, la linde que limita su terreno es el comienzo y el final del - su - mundo. Más allá de ella no hay labor y por lo tanto no hay ganancia, pues no hay propiedad. Frente a ello, el pastor debe sortear las fronteras entre campos ajenos discurriendo por las libertades que ofrecen las vías pecuarias: las cañadas, los cordeles, las veredas y las coladas. Estos canales terrestres articulan las reglas de su particular juego: comunican, construyen, unen naturalezas. De este modo, Careri termina apuntando que:

[...] Caín puede ser identificado con el homo faber, el hombre que trabaja y que se apropia de la naturaleza con el fin de construir materialmente un nuevo universo artificial, mientras que Abel, al realizar a fin de cuentas un trabajo menos fatigoso y más entretenido, puede ser considerado como aquel homo ludens tan querido por los situacionistas, el hombre que juega y que construye un sistema efímero de relaciones entre la naturaleza y la vida. (Ibídem, p. 24)

\section{Artista-pastor nómada (Imaginariamente)}

Este modelo citado por Careri podemos extrapolarlo al artista que se presta a alegorizar la narrativa externa que acompaña a la obra analizada en esta comunicación. Un artista que transita entre territorios de distinta índole y que, al igual que el pastor, también es móvil y es nómada; se desplaza con cierta dilación en un vasto campo imaginario por donde circunvalar aquellas problemáticas, intereses y presencias de los diferentes objetos de su investigación.

Este artista es ludens en cuanto a que no está atado a un terreno o territorio concreto ni le interesan los espacios limitados por aquellas proclamas en pos de la rentabilidad. No está ligado inexorablemente a un sistema faber, aquel imperante en los regímenes gobernados por el híper-productivismo. Un artista que cuestiona permanentemente el modelo hegemónico de las STEM, las siglas en inglés de Science, Technology, Engineering y Mathematics; aquella conjunción impuesta de materias que se ha 
Juan del Junco

conformado como selección de disciplinas necesarias para el capital y el productivismo, la cual:

[...] trata de normalizar la creación y la transdisciplinariedad dentro de los límites de la tecnología. Nos da la libertad de correr de acuerdo a nuestro antojo, en cualquier dirección y con total libertad, siempre que no tratemos de salir de la celda. El absurdo y lo excéntrico, la imaginación ilimitada, todos quedan excluidos de la celda. (Camnitzer, 2017, p. 18)

Nuestro artista es errante e itinerante, y milita en los márgenes de una mentalidad de producción mutable contraria a los sistemas normativos de una sociedad auspiciada por la utilidad para y por el capital, pues "el vagabundeo, tan poco tolerado en nuestras sociedades como el silencio, se opone así a las poderosas exigencias del rendimiento, de la urgencia y de la disponibilidad absoluta en el trabajo o para los demás" (Le Breton, 2017, p.22). De hecho, este artista "homo ludens" también deambula con parsimonia a través de ilimitados campos imaginarios conformados por sus preocupaciones, intereses o deseos epistemológicos. A diferencia del productor faber, posee la enorme fortuna de que mientras desarrolla su transitar se siente libre para dedicar cierto tiempo a disfrutar del placer de la observación y la contemplación. Puede, al igual que el pastor, sentarse en su piedra a observar ensimismado todo aquello que le rodea, esperando a que las diferentes ideas, proyectos y obras pasten a lo largo de un campo florido. Posteriormente, irá con su trabajo a un nuevo territorio, allí donde sea posible la experiencia dinámica; ya que, en cierto sentido, "el nómada sólo existe manteniendo viva la fusión entre propiedad y trabajo: el nómada entiende, porque lleva consigo su experiencia. [...] Sin pretender luchar por sí mismo contra la civilización, trabaja para mantener vivo un bien simbólico: el arte" (Celant, 1979, p. 57).

El artista de El lenguaje es nómada y posee la licencia para serlo. Debemos resaltar el término "licencia" ya que "el arte debe probar aún su utilidad. [...] los que lo practican se convierten en vagabundos, nómadas supervivientes que no encuentran ninguna patria entre los que se han hecho sedentarios" (Adorno y Horkheimer, 1998, p. 73). La licitación en el mundo de la híper-producción no es un asunto baladí, Rebecca Solnit (2015) apunta que "[...] muchas profesiones en muchas culturas, desde músicos hasta médicos, han sido nómadas, poseedoras de una suerte de inmunidad diplomática al conflicto entre regiones que mantiene a otros ligados a su tierra" (p. 36). A estos, debemos de añadir los pensadores, los escritores, los artistas... todos aquellos que han hecho bandera de un gen pedestre en los procesos de la creación, ya que:

en todas las épocas, el andar ha producido arquitectura y paisaje, y que esta práctica, casi olvidada por completo por los propios arquitectos, se ha visto reactivada por los poetas, los filósofos y los artistas, capaces de ver aquello que no existe y hacer que surja algo de ello. (Tiberghien, 2017, p. 9). 
Por otro lado, podríamos declarar que este artista-pastor de nuestro vídeo se aproxima a las posiciones de los pensadores cínicos en el sentido de que está más cercano a lo meramente natural que al modelo social imperante. Desoye las convenciones de la civilización y se apresura a enfrentarse a ellas desde una posición crítica. Va de lugar en lugar enunciando, verbalizando, (cuasi)ladrando. Se detiene en sus trayectos para emitir sonidos que no son otros sino códigos de un lenguaje. Un lenguaje críptico lanzado al aire que no espera sino ser captado por aquel que está realmente interesado en é, "pues cada uno se siente interpelado y criticado en sus costumbres, su actitud y sus convicciones" (Gros, 2014, p. 141). Para él no hay lugar fijo ni posesión, desdeña el espacio estático o sedentario donde pensar o enunciar y está siempre a la intemperie, ya que sólo a través de este estar en el mundo puede aprehender lo real. Su vagabundear está ligado a una relación sincera con el medio primitivo de la naturaleza:

[...] porque a él no le interesa buscar ni reconstruir más allá de las apariencias. Irá a encontrarla en la radicalidad de la inmanencia: justo debajo de las imágenes del mundo, busca lo que las sostiene. Lo elemental: lo único verdadero es el sol, el viento, la tierra y el cielo. (Ibídem, pp. 142-143)

\section{Artista- pastor nómada (fisicamente y transdisciplinario) en el paisaje experiencial}

Pero, lejos del plano de lo imaginario, el protagonista de El lenguaje - nuestro artistapastor- es también un homo ludens que ha abandonado físicamente el estudio. Al hacerlo se siente nómada, lejano del sedentarismo que se articula en aquellas materialidades de la producción artística. Vagabundeando de proyecto en proyecto decide desmaterializar la fisicidad de sus enunciados para otorgar predominancia a los procesos. Su modelo de producción se sostiene y se articula a través del concurso de una experiencia. En nuestro caso en concreto se desarrolla en una acción en el entorno natural que cuestiona y resignifica cualquier idea de un paisaje construido. En oposición a ello, toma partido por un paisaje por construir: un paisaje experiencial.

$Y$ es que, para llegar a realizar El lenguaje, anteriormente debemos construir y fabricar paisaje a partir de un espacio o un territorio dado. Este paisaje es un constructo cultural y social que según Alain Roger (2007) es claramente diferenciable del concepto país o de todo aquello que existe per se en el entorno natural y que nosotros percibimos. Roger nos dice que esta concepción de los lugares está profundamente artealizada: es el arte y el vasto mundo de las representaciones culturales quien lo ha definido $y$, al hacerlo determina nuestra forma de recepcionarlo y representarlo.

Ahora bien, en el caso que estudiamos, esta noción de paisaje no se articula únicamente a través del mundo de las representaciones procedentes de las 
humanidades; a ello debemos añadirle una primera intención inter y transdisciplinaria que transforma esencialmente la experiencia en el mismo. En nuestra acción por los espacios naturales media una fusión entre dos prácticas en apariencia exógenas: una artística - la primera de ellas o residente - y otra científica - la ornitología - la cual abordamos desde su estatus de ciencia social, desde la posición del amateur. En este sentido, es a través de un estar y un hacer en los intersticios de ambas disciplinas donde se produce la unión entre la artealización rogeriana y nuestra cientificación del país por el que transitamos. Ese modelo intersticial nos permite adoptar una posición mixta, donde cabe el observador o focalizador: aquel que atiende a los elementos de la naturaleza desde un régimen microscópico en un sistema conformado por unidades individuales diversas; pero, a su vez, también cabe aquel que entiende un paisaje macroscópico, un todo que se establece en los márgenes de las representaciones arquetípicas.

Ante estos dos modelos epistemológicos heterodoxos, la experiencia intersticial capaz de propiciar la fusión transdisciplinaria es el caminar. Es por ello que creemos que nuestra manera de aproximarnos a observar y aprehender el país-paisaje -ya artealizado y cientificado- se articula mediante este concepto procedimental que habita en las dos disciplinas. Así, ambas figuras - algunos artistas y aquellos ornitólogos que realizan trabajos de campo- consideran el caminar como proceso o como medio; por lo que, para nosotros, caminar se convierte en método, en acción y vivencia, de ahí que defendamos nuestro concepto de paisaje experiencial.

Esta manera confluyente de acción en la naturaleza atiende a la par a los procesos dinámicos de ambas disciplinas. Por un lado, adopta las metodologías de campo de la ornitología ortodoxa: sobre todo aquellos métodos denominados "lineales", como el "itinerario de censo" y el "taxiado" (Tellería, 1978, p. 22). Unas metodologías de observación y escucha de aves que se realizan mediante trayectos a pie por aquellos territorios que son objeto de estudio. Por el otro atiende también a las prácticas de los artistas caminantes, aquellas partes no objetuales de las obras que desmaterializan el objeto artístico y que provienen del cambio acecido en la escultura tras el minimalismo: en el celebre abatimiento del plano vertical hegemónico hacia un nuevo plano horizontal que desborda los límites de las galerías y museos (Lippard, 1983, p. 123).

La desmaterialización de la obra ha de propiciar la búsqueda de nuevos lenguajes para los artistas. Así, por poner un ejemplo, Hamis Fulton crea sus Walk-texts, del cual nos dice: "[...] el precio que pago por no imitar la naturaleza es proporcionar información escrita sobre mis paseos" (Morrison y Fulton, 2000, p. 191). De esta manera desplaza la atención hacia un nuevo modelo paradigmático de enfrentarse y entender las relaciones con lo natural en el ámbito artístico. Para Fulton "caminar es encontrar espacio, tierra, árboles, vistas, sonidos, olores, animales, huellas, frío, etc. - mientras 
que realizar el Walk-Text es registrar esos encuentros, pero no replicarlos" (Macpherson, 2000, p. 17).

Como hemos podido apreciar, nuestra manera de abordar la experiencia en la naturaleza se basa en articular equilibradamente una relación bimodal entre dos modelos antagónicos -uno subjetivo y otro objetivo. Ahora bien, es cierto que la ciencia no permite la inclusión de las emociones en sus enunciados, aunque es más que obvio que el placer que produce el acto de la observación junto a las posibilidades de colmar los deseos heurísticos están presentes en el ánimo de cualquier científico que estipule sus investigaciones en los entornos naturales. Baste leer un pequeño pasaje del libro Viaje de un naturalista alrededor del mundo, el viaje que realizó Charles Darwin en el Beagle. Tras desembarcar en Salvador de Bahía, Brasil, en febrero de 1832, "después de haber andado errante por espacio de algunas horas", el británico exclama:

¡Qué delicioso día! Pero la palabra delicioso es harto débil, para expresar los sentimientos de un naturalista que por primera vez vaga por un bosque brasileño. [...] Todo el que ame á [sic] la Historia Natural siente en un día como éste un placer y un júbilo más intensos que puede prometerse experimentar de nuevo" (Darwin, 1981, pp. 26-27).

Darwin vaga, realiza una deriva sin rumbo por los territorios que le son de interés para sus estudios y expresa con admiración su placer tras la caminata. En esa falla del sistema positivista es donde creemos que podemos insertar una posibilidad de emoción: es ahí donde se nos permite simbolizar y alegorizar, donde podemos desarrollar la acción transdisciplinaria. Y es que, al igual que Fulton, en nuestra acción en el paisaje experiencial propiciamos el encuentro con los elementos colaterales que nos ofrecen los territorios transitados, y, así, aplicar nuestro foco de interés en el registro de los mismos.

\section{Registro de un paisaje desde la posición del otro cultural y posterior giro en significancia}

Esta manera de articular paisaje en torno a los cruces disciplinares o estos viajes entre campos epistemológicos confluyentes tienen también como base lo que Hal Foster (2001) denomina "una alteridad radical del otro cultural" (p. 179). De este modo, se produce un intercambio de influencias, un trasvase de flujos de conocimiento donde, al igual que en los estudios culturales, "a menudo se extiende el objeto de estos estudios, el otro cultural, que es reconfigurado para reflejar una imagen ideal del antropólogo, el crítico o el historiador" (Ibídem, p.185). El cruzamiento genera la aparición de modelos interdisciplinarios, de adopción y cooptación de métodos exógenos en las prácticas artísticas de las últimas décadas del siglo $\mathrm{XX}$, sobre todo a partir del concurso del arte 
conceptual de finales de la década de los sesenta y principios de los setenta. En la actualidad, según Dieter Roesltraete (2013), la importancia de la investigación académica en el periodo formativo de los artistas junto al creciente y decisivo aumento del acceso a la información han suscitado un deseo epistemológico hacia otras disciplinas adyacentes. La suma de estas causas ha promovido "la reciente reconfiguración del arte como un tipo de investigación y del artista como productor de conocimiento o trabajador de conocimiento" (p. 10).

Así, nuestra experiencia en el paisaje nos lleva a estudiar cada elemento de encuentro desde un posible régimen de estudio en su posible disciplina de acción. Uno de los componentes de este paisaje habitado es la potencialidad de un territorio compartido con otros actores. De este modo, entre los entes que también hacen y conforman paisaje aparecen los cabreros y sus rebaños, con los cuales apuntamos una relación de proximidad, ya que, de alguna manera, ambos coexistimos y convivimos en nuestro paisaje experiencial común. El cabrero para nosotros es una parte más a estudiar de ese todo general que se denomina entorno natural. Su figura puede ser entendida como un eslabón intermedio entre el hombre y el animal, entre ser humano y medio físico, entre civilización y naturaleza, aportando al territorio identidad cultural.

Visto esto, nuestra forma de aproximarnos a la observación y estudio de la figura del cabrero se estipula desde el registro de sus especificidades. Es por ello que el video muestre a priori un hipotético análisis de sus lenguajes y códigos propios, en los márgenes de lo que podría parecer un trabajo etnográfico o antropológico, a través de un modo de enunciar desde el "otro cultural". El montaje final de la obra intercala una imagen de un paisaje de las montañas malagueñas con los diferentes sonidos que emiten los cabreros para comunicarse con las cabras (Fig 1). A su vez, estas imágenes se montan intermitentemente con un largo plano donde aparece un rebaño de cabras acercándose paulatinamente desde la lejanía en un camino (Fig. 2). Este montaje sistemático, aún siendo monocanal, nos parece análogo a la disposición de imágenes en cuadrícula, un sistema de ordenación visual que presenta connotaciones de las disciplinas científicas. Martha Rosler (2007) apunta sobre ella: "me atraía el poder formal y taxonómico de las cuadriculas (aunque mi uso de las cuadrículas conserve un eco no muy remoto del constructo científico o matemático, su uso en el arte suele conllevar únicamente connotaciones de "cientifismo" y rigor)" (p. 13). 


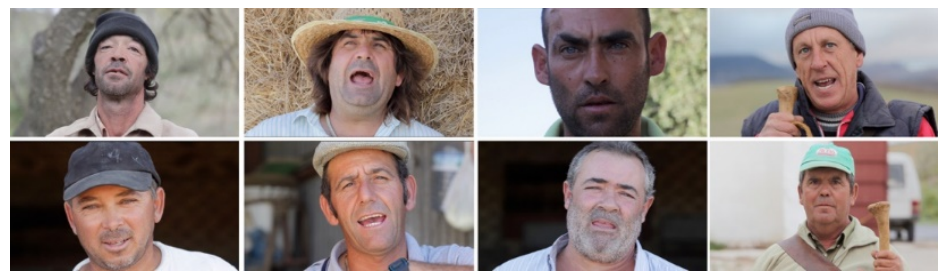

Fig. 1: Xxxx Xxx Xxxxx El Lenguaje, 2013, diferentes stills de video.

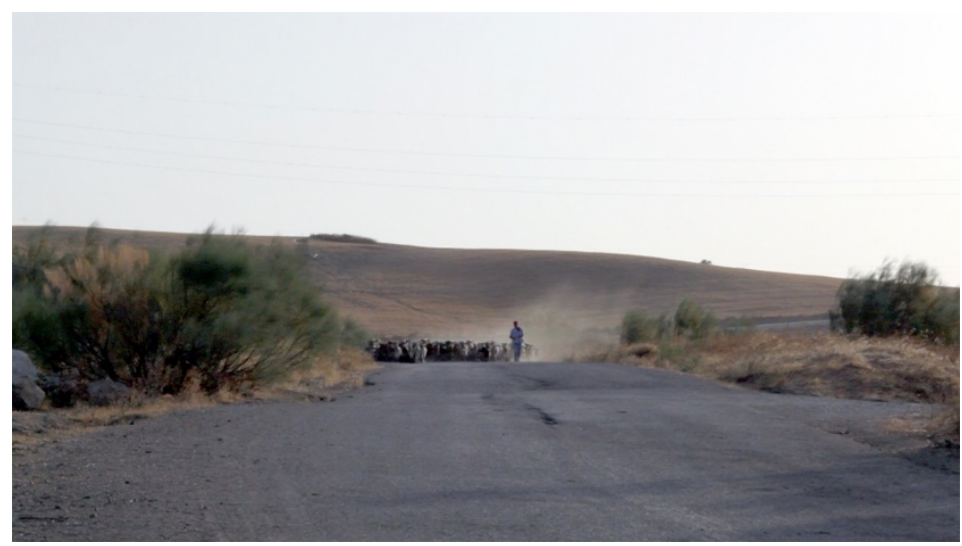

Fig. 2: XXXXXXXXXXXX El Lenguaje, 2013, still de video.

Así, el modelo de montaje - su orden rítmico, su frontalidad y estatismo en cuanto a los planos de cámara, o la neutralidad y casi desaparición del autor - nos remite a un deseo de distanciamiento que bien podría atribuirse a los formatos característicos del trabajo de documentación etnográfica o antropológica. Esta estrategia de creación se hace bien patente pues resulta del cruce disciplinar, o más concretamente, deriva de la cooptación y confiscación de métodos y lenguajes de ámbitos ajenos: una característica de las metodologías interdisiciplinarias "de importación" (Pombo, 2017, p. 38). Sin embargo, esta utilización de procesos, lenguajes y códigos importados no se afianza a través de su posicionamiento en los límites de su función original, ya que es en nuestra capacidad de reutilización y en nuestra operatividad para su transformación donde se encuentra el giro en significancia.

Este montaje concadenado de sonidos de los cabreros, territorio y rebaño es para nosotros una forma de articular la alegoría, la cual anunciamos así en la explicación que acompañaba a su exposición: 
Juan del Junco

El cabrero y su rebaño se comunican constantemente, su lenguaje críptico es apto únicamente para los iniciados. Ininteligible para el resto, al no iniciado sólo le puede producir asombro y excitación. La cabra, al igual que un connoiseur, no sólo lo entiende, si no que lo acata y lo hace suyo como parte de su existencia. (Xxx Xxxxx, s.f.)

Ahí está la clave del proceso alegórico: en la resignificación de las imágenes y en la contaminación disciplinar fecunda de su montaje. Y es que, si bien podemos creer que estamos ante un enunciado científico, de orden etnográfico, la obra lleva adherida una capa a priori invisible de significado, una narrativa externa que desarticula toda objetividad presupuesta; como apunta Juan Francisco Rueda (s.f.):

He ahí una de las preocupaciones del artista - ¿de todo artista? -: la capacidad para comunicar, la duda acerca de si se consigue la comunicación y -si me permiten - la comunión. Cabrero y cabras comparten ese código de sonidos, voces y gestos que, para la mayoría, resulta ajeno e indescifrable, haciéndola sentir al margen de esa comunidad que aquí se metaforiza en el rebaño, en los espectadores/usuarios que atienden al artista.

\section{Conclusiones}

Como hemos tratado de demostrar, la obra videográfica El Lenguaje se articula en varios planos que operan en pos de la creación de una alegoría. Como primer dato, en su generatividad se vehicula una práctica inter y transdiciplinaria fruto de la yuxtaposición y fusión de dos disciplinas exógenas: el arte contemporáneo y la ornitología en su forma amateur. Así, como hemos visto, el concepto instrumental que hace posible la interacción entre ambos campos epistemológicos heterodoxos - uno de índole subjetiva y otro objetiva - es la acción de caminar, presente tanto en las metodologías de campo científicas como en algunas prácticas artísticas que tienen como fin la desmaterialización de la obra de arte. Este modelo de transitar el paisaje, que podemos denominar paisaje experiencial, promueve el encuentro y la observación de los distintos elementos que conforman el entorno natural. Uno de ellos es el cabrero, el cual añade valor de identidad cultural al territorio. Esta figura es la que nos es útil para montar la alegoría, la cual es construida desde la posición del "otro cultural". Así, mediante un registro de corte objetivo, a modo de estudio etnográfico o antropológico, se presenta la obra: editada desde la frontalidad y bajo la casi desaparición del autor. El giro en significancia radica en que esta fachada (cuasi)científica no hace sino enmascarar una narrativa externa: aquella que trata sobre el propio estatus del artista y de su capacidad de comunicación y enunciación. Así, la alegoría se establece en torno a un paralelismo entre la propia condición nómada de los pastores y un posible estado de movimiento permanente del artista, tanto 
imaginariamente - en sus divagaciones - como físicamente - en la era del artista postestudio.

\section{Referencias}

Adorno, T. y Horkheimer, M. (1998). Dialéctica de la llustración. Fragmentos filosóficos. Editorial Trotta.

CARERI, F. (2017). Walkscapes. El andar como práctica estética. Gustavo Gili.

FOSTER, H. (2001). El retorno de lo real. Akal.

Camnitzer, L. (2017). Prólogo. En M. Acaso y C. Megías, Art Thinking. Espasa. 11-18.

Celant, G. (1979). Mario Merz: The artist as a nomad. Artforum. Vol. 18 (no 18), 52-58. https://www.artforum.com/print/197910/mario-merz-the-artist-as-nomad-35859.

DARWIN, C. (1981). Viaje de un naturalista alrededor del mundo. Amigos del Círculo Bibliófilo.

Gros, F. (2014). Andar. Una filosofía. Gustavo Gili.

Xxxx Xxx Xxxxx. [xxxx] (5 mayo 2021). El lenguaje [Video]. Vimeo. https://vimeo.com/122668402.

LE BRETON, D. (2017). Elogio del caminar. Siruela.

LIPPARD, L. (1983). Overlay. Contemporary Art and the Art of Prehistory. Panteon Books.

MACPherson, A. (1978). "Sensous singularity ». Hamis Fulton's Cairngorms Walk-Texts. Critical Survey, 29 (1), 12-32. https://abdn.pure.elsevier.com/en/publications/sensuous-singularityhamish-fultons-cairngorm-walk-texts.

Morrison, G y Fulton H. (2000). Interview with Hamish Fulton. En H. Fulton, Wild life. Pocketbooks. 7-12.

Ромво, О. (2013). Epistemología de la intediscinplinariedad. La construcción de un nuevo modelo de comprensión. Interdisicplina $\quad l, \quad 1$ 2150.http://revistas.unam.mx/index.php/inter/article/view/46512.

Roelstraete, D. (2013). Notas de campo. Sobre el imaginario arqueológico en el arte. En V. Torrente, Arqueológica. Matadero Madrid. 10-15.

Roger, A. (2007). Breve tratado del paisaje. Biblioteca Nueva.

Rosler, M. (2007). Un nuevo paseo por el Bowery. En M. Rosler y J. Carrillo (eds.), Imágenes públicas. La función política de la imagen. Gustavo Gili. 10-32.

RUEDA, J. F. (s.f.). El lenguaje. http://www.xxxxxxxxx/el_lenguaje.htm [Consulta: 8 mayo 2021].

SOLNIT, R. (2015). Wanderlust. Una historia del caminar. Penguin Random House. 
Juan del Junco

TelleRía, J. L. (1978). Introducción a los métodos de estudio de las comunidades nidificantes de aves. Ardeola, 24, 19-69.

Tiberghien, G. (2017). La ciudad nómada. En F. Careri, Walkscapes. El andar como práctica estética. Gustavo Gili. 7-12.

Xxxx xxx Xxxxx. (s.f.). El lenguaje. http://www.xxxxxxxxx/el_lenguaje.htm [Consulta: 8 mayo 2021]. 